\title{
Gabrielle Roy, Il viaggio di veline - André Carpentier, Rue Saint-Denis
}

\section{Simona Rossi}

\section{Q OpenEdition \\ 1 Journals}

\section{Edizione digitale}

URL: http://journals.openedition.org/studifrancesi/33817

DOI: $10.4000 /$ studifrancesi.33817

ISSN: 2421-5856

\section{Editore}

Rosenberg \& Sellier

\section{Edizione cartacea}

Data di pubblicazione: 1 décembre 2005

Paginazione: 686

ISSN: 0039-2944

\section{Notizia bibliografica digitale}

Simona Rossi, «Gabrielle Roy, I/ viaggio di veline - André Carpentier, Rue Saint-Denis», Studi Francesi [Online], 147 (XLX | III) | 2005, online dal 30 novembre 2015, consultato il 18 avril 2021. URL: http:// journals.openedition.org/studifrancesi/33817 ; DOI: https://doi.org/10.4000/studifrancesi.33817

Questo documento è stato generato automaticamente il 18 avril 2021.

\section{(c) (i) (9)}

Studi Francesi è distribuita con Licenza Creative Commons Attribuzione - Non commerciale - Non opere derivate 4.0 Internazionale. 


\title{
Gabrielle Roy, Il viaggio di veline - André Carpentier, Rue Saint-Denis
}

\author{
Simona Rossi
}

\section{NOTIZIA}

GABRIELLE ROY, Il viaggio di veline, cura e postfazione di Novella NOvELLI, traduzione di Maria Rosa BALDI, Collezione Laurentide, Roma, Sinnos editrice, 2004, pp. 74. ANDRÉ CARPENTIER, Rue Saint-Denis, cura e postfazione di Anna Paola MOSSETTO, traduzione di Lucia Bonato, Collezione Laurentide, Roma, Sinnos editrice, 2004, pp. 111.

1 I due volumi fanno parte di un progetto di traduzione in italiano di opere brevi quebecchesi finanziato e sostenuto dal CISQ (Centro Interuniversitario di Studi Quebecchesi), con la finalità di promuovere e diffondere la conoscenza della letteratura quebecchese nel nostro paese.

2 Il viaggio di Éveline (1982) e Rue Saint-Denis (1978), rispettivamente un romanzo breve di Gabrielle Roy e una raccolta di novelle di André Carpentier, inaugurano l'iniziativa, il primo curato da Novella Novelli e la seconda da Anna Paola Mossetto. Caratterizzate da una traduzione chiara, precisa ed efficace, le due opere rappresentano perfettamente la vivacità e l'eterogeneità della letteratura quebecchese. La storia di Éveline è delicata $\mathrm{e}$ profonda: una dolce, minuta, generosa vecchietta del Manitoba che ha trascorso tutta la vita ad occuparsi degli altri, finalmente si concede il viaggio dei suoi sogni, spinta dalla lettera di un fratello lontano che le chiede di raggiungerlo in California. Costretta su un autobus per giorni e giorni, per lei cominciano così una nuova vita e un nuovo tempo, fatti di $\mathrm{Km}$, di paesaggi desertici ed innevati, di compagni di viaggio attenti e premurosi, di storie soprattutto. Perché Éveline non tace un istante, non fa che parlare e raccontare di sé, dei suoi ricordi, della sua infanzia, dei giochi e degli scherzi col fratello che non vede più da tempo. E così, ogni storia ne genera un'altra e le parole si moltiplicano in girandole di storie, tanto che ben presto l'autobus si trasforma in un'immensa storia collettiva che viaggia attraverso il Canada. E all'arrivo Éveline 
troverà ad attenderla ancora altre storie: il fratello Majorique è morto, ma negli ultimi anni della sua vita ha riunito attorno a sé la maggioranza dei suoi innumerevoli figli, che ora abitano gli uni accanto agli altri in casette dal tetto a punta e dall'orticello ordinato sulle colline circostanti. Chi vive lontano, invece, arriva appositamente per quel funerale che tutto sembra fuorché un funerale, allora le differenze si mescolano e si amalgamano, diventando una cosa sola. È una tribù che trabocca d'amore e di storie da raccontare, quella a cui si trova di fronte Éveline, e alla fine, quando la bara di Majorique viene calata nella fossa che "esala un odore di terra forte e dolce" (p. 58), la donna gli è profondamente grata per quella famiglia che le dona, "variegata e strana come l'umanità stessa" (p. 58). Gli è grata per tutto ciò che non aveva mai potuto vedere e che ora ha visto, gli è grata per le voci, per le storie, per la distesa scintillante e bellissima dell'oceano che si apre davanti ai suoi occhi stupiti. È evidente che Éveline ha portato a compimento il suo percorso iniziatico, che è uscita dal suo bozzolo e ha trovato la calma perfetta. Romanzo dalla forte connotazione metaforica, che riflette sulla possibilità di apertura della letteratura quebecchese all'Altro pur senza dimenticare le sue radici, Il viaggio di Éveline è un piccolo, grande testo ottimista che vale sicuramente la pena di leggere.

Protagonista della raccolta di novelle di André Carpentier è invece una via, come si capisce bene dal titolo, Rue Saint-Denis, vera e propria arteria nel cuore pulsante del Quartiere Latino di Montréal, crocevia di gente, storie, piedi, occhi, giacche, desideri e pensieri. È esattamente in questo scenario brulicante di vita, tra bar e ristoranti, librerie e negozi di antiquariato, che l'autore - famoso per aver inventato un originale genere fantastico, in cui si mescolano autobiografia, orrore e comicità - fa respirare, mangiare, lavorare, passeggiare, litigare i suoi personaggi. Sognatori e visionari, spesso sull'orlo di una crisi di nervi, essi vivono vite assolutamente usuali, ma dove l'insolito e l'inspiegabile sono sempre dietro l'angolo. Così, il vecchio George du Tarne, cinese emigrato in Québec, determina le sorti di molte persone, muovendo semplicemente il dito su un immaginario mappamondo sorto dal nulla; Mado, un'insegnante un po' frivola dalle mani bucate, sparisce in seguito all'acquisto di uno strano cofanetto; una nave assassina, dopo aver ucciso diversi individui, fa annegare anche Phil, l'ispettore che svolgeva le indagini; case, negozi stregati e sogni premonitori fanno capolino qua e là con molta naturalezza, quasi fossero un risvolto assolutamente normale della quotidianità. In qualche modo legate ai tempi moderni, abituati al bizzarro e all'inconsueto, queste novelle celano una profonda indagine della psiche umana, che si spinge nell'emotività, nei desideri, nelle ansie e paure di ognuno di noi. Il progetto di una collana di traduzione di testi brevi quebecchesi elaborato dal CISQ non poteva trovare migliore inaugurazione di questi due piccoli capolavori, sognanti e al tempo stesso ancorati alla realtà. 